\title{
40 anos da "Virada" do Serviço Social: história, significados
}

\author{
40 years of the "Virada" of social work: \\ history, meanings
}

\author{
Maria Carmelita Yazbek \\ (D) https://orcid.org/0000-0002-4785-472X \\ Maria Inês Bravob \\ (1) https://orcid.org/0000-0003-2347-0518 \\ Raquel Raichelis ${ }^{a}$ \\ (D) https://orcid.org/0000-0003-3275-3755
}

ste número especial da Revista Serviço Social \& Sociedade vem a público em um contexto de profundas transformações societárias que nos colocam, como afirma Antunes (2018, p. 10), frente à "uma nova era de devastação, uma espécie de fase ainda mais destrutiva da barbárie neoliberal e financista que almeja a completa corrosão dos direitos do trabalho em escala global".

Nesse contexto, em especial nas últimas décadas, o capital financeiro assumiu o comando no processo de acumulação e "não mais apresenta fronteiras de qualquer ordem” (Marques, 2018, p. 110-113). Tais transformações, observadas na esfera da acumulação capitalista, trazem seus impactos para o mundo da política, do trabalho, na "questão social” e nas Políticas Sociais, âmbitos da intervenção profissional do assistente social e nos alcançam cotidianamente, pois a desigualdade e a concentração de renda que se intensificam nas atuais formas de acumulação capitalista trazem como consequência a radicalização da questão social. Efetivamente o capitalismo em crise radicaliza a questão 
social, ampliando o "desemprego estrutural, além da precarização e deterioração da qualidade do trabalho, dos salários e das condições em que ele é exercido, que se agravam ainda mais se considerando os recortes de gênero, geração, raça e etnia" (Raichelis, 2018, p. 51).

No Brasil, chegamos, em 2018, a 54.8 milhões de pobres, sendo que 14.830 milhões de brasileiros estão em situação de pobreza extrema (aumento de 11,2\% em relação ao índice de 2016, conforme dados do IBGE). Crescem as desigualdades socioeconômicas entre pessoas de diferentes etnias e raças. Cresce o genocídio contra pretos e pardos que enfrentam muito mais dificuldade para encontrar empregos, vagas em creches e moradias. O número de trabalhadores informais superou o conjunto de empregados formais. As ocupações informais de baixa remuneração e ganho instável, ao lado do desemprego, permeiam a vida das classes trabalhadoras em nossa sociedade. Ainda como aponta Iamamoto em seu artigo neste número, trata-se de um tempo de radical privatização, que destrói direitos trabalhistas, a previdência social, a universidade pública e o ensino superior federal público, pressionando sua privatização com o contingenciamento total ou parcial de verbas.

É inserida neste contexto, e a partir da interlocução com essa realidade de crise estrutural do capital, no qual se engendram outras crises, uma nova política e uma sociabilidade conservadora. É aí que situamos o Serviço Social brasileiro e alguns dos desafios que este deve enfrentar na resistência e preservação de conquistas desses últimos 40 anos.

Como sabemos, nas últimas quatro décadas "o Serviço Social brasileiro construiu coletivamente um projeto para a profissão, forjado nas lutas dos movimentos sociais e articulado a um projeto societário anticapitalista. Esse projeto significou uma ruptura com o pensamento conservador que marcou a origem da profissão, sob influência do pensamento social da Igreja e de teorias de cariz positivista e funcionalista, e se construiu à luz do pensamento de autores marxistas e fundamentalmente a partir da Teoria Social de Marx e de suas explicações mais abrangentes e totalizantes acerca da vida social e de seu sentido histórico" (Yazbek, 2017, p. 102). 
A partir dos anos 1970 ocorreram importantes acontecimentos em diferentes âmbitos: na formação; na produção e divulgação dos conhecimentos a respeito da profissão; na virada nas entidades da categoria com um novo projeto para o Serviço Social e a perspectiva de articulação entre elas. Estes fatos foram fundamentais para a ruptura no Serviço Social brasileiro e latino-americano com a perspectiva conservadora.

Na formação, ressalta-se a introdução do Serviço Social no âmbito da Pós-Graduação stricto sensu no Brasil com a criação dos primeiros mestrados na área em 1972, nos Programas de Pós-Graduação em Serviço Social da PUC-SP e da PUC-RJ; a criação de novas Unidades de Ensino nas universidades públicas; a ampliação do número de professores através de concurso público; maior integração entre as diversas áreas de conhecimento e Departamentos cujos professores passaram a ser responsáveis por matérias básicas do currículo do Serviço Social: sociologia, economia, psicologia e outros. No interior das Universidades Públicas a integração com outras áreas de conhecimento se fez também nas instâncias do Movimento Estudantil.

No Brasil, a produção de conhecimentos e divulgação do Serviço Social crítico, com fundamentação marxista, começa a partir de meados dos anos 1970, basicamente em 1979, advindas das primeiras dissertações de mestrado que foram publicadas pela Cortez Editora com novos debates e problematizações sobre a profissão e as demandas que emergiam na realidade brasileira e latino-americana. A Revista Serviço Social \& Sociedade também tem seu primeiro número em 1979 com artigos que vão problematizar e contribuir para o maior adensamento crítico do Serviço Social e sua ruptura com o conservadorismo.

No campo das entidades ocorre a mudança de direção nos sindicatos e associações profissionais de assistentes sociais ampliando para a criação da CENEAS e, posteriormente, ANAS. Na formação tem-se a virada na ABESS/ABEPSS com a aprovação do novo currículo na Convenção de Natal, em 1979, aprovado pelo MEC apenas em 1982. No conjunto CFAS/CRAS as reações vão ocorrer a partir de 1981 nos CRAS e 
a partir de 1983, no CFASS, com a eleição de uma direção de centro-esquerda e que teve como marco a promulgação do Código de Ética de 1986 que propõe o compromisso do Serviço Social com a perspectiva da classe trabalhadora.

Todos estes temas serão objeto dos oito artigos que compõem este número especial, voltado à revisão crítica da história de rupturas do Serviço Social com o legado conservador, buscando extrair ensinamentos para enfrentar a atual conjuntura adversa que estamos vivenciando.

Os dois artigos que abrem a coletânea tratam a temática de forma abrangente e fornecem os elementos fundamentais para a caracterização da temática central, ou seja, a história, os significados e os desafios dos 40 anos da "Virada" do Serviço Social.

Nessa perspectiva, o trabalho de Mauro Luis Iasi vai buscar explicações para o tempo presente na Formação Social Brasileira e nas particulares condições do desenvolvimento desigual e combinado do capitalismo no país. Para o autor, um diagnóstico crítico do tempo presente deve considerar os processos de formação do país desde a colonização, um empreendimento mercantil que caminha na direção de uma economia composta de senhores e escravos, na qual as marcas do patrimonialismo-paternalista vão plasmar a sociedade brasileira. Traço da formação social brasileira, a conjugação do "avanço" com o "atraso" assegurou o sucesso da dominação burguesa desde sempre, apesar do período de conciliação de classes e de enfrentamento à pobreza, representado pelos governos de Lula e Dilma, com sua forma de investimento no social, denominada por alguns autores de neodesenvolvimentismo, expressa especialmente nos Programas de Transferência de Renda Condicionada (PTRC), no aumento do salário mínimo e nas Políticas Sociais com destaque para a Assistência Social. Contexto que se caracterizou pela combinação de "medidas de natureza oposta", e a articulação de dubiedades que permearam a política social brasileira. De um lado as tendências a focalizar e privatizar, e de outro a perspectiva de construção de direitos garantidos constitucionalmente. 
O caráter predatório das relações coloniais e do escravismo deixou, sem dúvida, suas marcas na história do país e implantou bases importantes na construção da lógica que vem presidindo a expansão do capitalismo dependente na periferia em tempos mais recentes.

$\mathrm{O}$ artigo de Marilda Iamamoto aborda a história e memória do III Congresso Brasileiro de Assistentes Sociais (CBAS), trazendo sua reflexão para o tempo presente e os desafios contemporâneos. A autora sustenta que o III CBAS é um marco na recusa do conservadorismo no Serviço Social brasileiro e destaca que este encontro foi a primeira e tardia manifestação massiva da categoria dos assistentes sociais contra a ditadura militar-empresarial. Vai ressaltar as diversas mobilizações de trabalhadores e entidades da sociedade civil que em aproximação com as lutas, organizações e movimentos sociais faziam a defesa dos direitos e projetos societários das classes subalternas, na criação de forças de resistência à ditadura do grande capital e no apoio ao processo de construção democrática. Destaca também as forças acadêmico-profissionais acumuladas pelo Serviço Social latino-americano e assistentes brasileiros que foram decisivas para a "virada" do Serviço Social.

Na sequência de sua análise, salienta os desafios presentes para o Serviço Social. Considera fundamental a preservação de conquistas da profissão nos últimos quarenta anos, mas ressalta que é preciso reconhecer que o Serviço Social no Brasil tem vivido um duplo e contraditório movimento. Apoiando-se em Netto (1996) afirma que o mais representativo desse movimento foi o processo de ruptura teórica e política da profissão com o lastro conservador de suas origens; entretanto, na contramão, verificou-se o revigoramento de uma reação (neo)conservadora aberta e/ou disfarçada, apoiada na negação da sociedade de classes. Ao enfrentar o ressurgimento de um projeto conservador no Serviço Social, a autora salienta que este parte de uma idealização do passado nos moldes do Social Work (Serviço Social de Casos, Serviço Social de Grupo e Desenvolvimento de Comunidade), considerado como "modelo" de profissionalização, apresentado como neutro, apolítico e técnico como suporte para a "intervenção". Ao mesmo tempo, na conjuntura social e 
histórica em que se inscreve o trabalho profissional não são analisadas nem são reconhecidas a politização à direita e a militância religiosa presentes na atualidade.

Iamamoto conclui sua reflexão destacando que:

"Esses tempos adversos, exigem dos assistentes sociais recriar seu trabalho considerando tanto sua contribuição na reprodução material dos sujeitos, expressa na prestação de serviços sociais de qualidade a partir de políticas públicas, quanto sua dimensão educativa que incide na cultura das classes subalternas: nas maneiras de ver, viver e sentir a vida, fortalecendo a dimensão coletiva das lutas sociais."

Os demais textos da Revista contribuem para ressaltar aspectos desta caminhada histórica do Serviço Social e algumas singularidades.

O artigo de Rita Meoño Molina, atual presidente da Associação Latino-Americana de Ensino e Pesquisa no Serviço Social (ALAEITS), aborda o Serviço Social na América Latina ressaltando que a região vive um momento de brutal regressão social, através das estratégias do neoliberalismo que visam enfraquecer as estruturas democráticas e os sistemas de proteção social na região. Nesse contexto, o trabalho social precisa assumir diversos desafios na defesa radical dos direitos humanos, sendo cada vez mais crítico e impulsionado pelos ideais dos movimentos sociais de resistência.

Josiane Soares Santos aborda em seu texto o trato conservador da "questão social" e as lutas sociais do tempo presente, ressaltando os desafios para o Serviço Social no Brasil. A autora aborda a crise econômica e política que se agravou, com ares de calamidade pública, a partir de março de 2015 e os desdobramentos que culminaram no impeachment da Presidente Dilma e início do ilegítimo governo Temer. Desdobra sua análise nos cem dias do governo Bolsonaro, caracterizando sua agenda ultraneoliberal e a centralidade que assume a contrarreforma da Previdência, fazendo um chamamento para a importância política da resistência nas ruas, no trabalho, nas atividades coletivas! 
Dois artigos têm como foco a importância da Revista Serviço Social \& Sociedade da Cortez Editora. Raquel Raichelis et al. realizam um balanço dos 40 anos ininterruptos deste periódico e sua contribuição ao pensamento crítico da profissão. Esther Lemos, atual presidente da ABEPSS, ao apresentar a contribuição da ABEPSS para a formação profissional e a pesquisa, constrói um caminho de volta na produção intelectual da área publicada na Revista Serviço Social \& Sociedade por destacadas/os pesquisadoras/es assistentes sociais, para evidenciar e apreender os nexos da pesquisa e da produção do conhecimento como forma de resistência e ruptura com o conservadorismo construída pela categoria.

Os dois últimos artigos vão enfatizar dois processos que deixaram marcas na renovação do Serviço Social brasileiro. O de autoria de Rosângela Batistoni apresenta resultados de uma pesquisa de reconstrução histórica do projeto da Escola de Serviço Social da Universidade Católica de Minas Gerais e sua influência na reforma curricular e em outras propostas do Serviço Social crítico brasileiro. O projeto da Escola se afirma pela sua aproximação à tradição marxista, realizada sob adversas condições políticas da sociedade e da universidade brasileiras sob a ditadura empresarial-militar de 1964. O artigo de Isaura Aquino, também fruto de pesquisa, analisa a participação do CBCISS no Movimento de Reconceituação e no Congresso da Virada, ressaltando a contribuição desta entidade para a renovação conservadora da profissão, denominada por Netto de Modernização Conservadora.

A Revista conta também com uma homenagem realizada ao Sr. José Xavier Cortez - presidente da Cortez Editora, realizada no $12^{\circ} \mathrm{Se}-$ minário anual de Serviço Social: Renovação e os 40 anos do Congresso da "Virada" no Serviço Social brasileiro. Memória, história e desafios contemporâneos, ocorrido no Teatro da Pontifícia Universidade Católica de São Paulo (TUCA), em 06 de maio de 2019, promovido pela Cortez Editora. A saudação em nome do Serviço Social brasileiro foi feita por Marilda Villela Iamamoto.

Desta edição especial constam ainda uma resenha do livro: Visita amigável entre os pobres: um manual para trabalhadores da caridade, de 
Mary Ellen Richmond, elaborada por Charles Toniolo; e um Manifesto de celebração dos 10 anos do curso de Serviço Social da Universidade Federal de São Paulo (Unifesp - Campus Baixada Santista).

Os diversos artigos desta edição especial da Revista Serviço Social \& Sociedade, que recuperam a história dos 40 anos da Virada do Serviço Social, são um importante dossiê para todas/os que têm como compromisso analisar a realidade atual para transformá-la, como afirmava Marx. Constitui, portanto, uma ferramenta de resistência ao desmonte dos direitos nesse tempo de crise estrutural do capitalismo, de expressões cotidianas da barbárie com mudanças regressivas em todas as dimensões da vida social.

O desafio está posto: continuar na luta coletiva fortalecendo o projeto ético-político do Serviço Social brasileiro e a articulação com os movimentos sociais, na defesa de uma outra sociabilidade, na perspectiva da emancipação política tendo como horizonte a emancipação humana.

\section{Referências}

ANTUNES, Ricardo. Prefácio. In: RAICHELIS, Raquel; VICENTE, Damares; ALBUQUERQUE, Valéria (Orgs.). A nova morfologia do trabalho no Serviço Social. São Paulo: Cortez Editora, 2018.

IANNI, O. A ditadura do grande capital. Rio de Janeiro: Civilização Brasileira, 1981.

MARQUES, Rosa. Capitalismo financeiro e as Políticas Sociais: a nova face da contemporaneidade. In: RAICHELIS, Raquel; VICENTE, Damares; ALBUQUERQUE, Valéria (Orgs.). A nova morfologia do trabalho no Serviço Social. São Paulo: Cortez Editora, 2018.

NETTO, José Paulo. Ditadura e Serviço Social: uma análise do Serviço Social no Brasil pós-64. São Paulo: Cortez Editora, 1994.

. Ditadura e Serviço Social: uma análise do Serviço Social no Brasil pós-64. São Paulo: Cortez Editora, 2015.

. Transformações societárias e Serviço Social: notas para uma análise prospectiva da profissão no Brasil. Revista Serviço Social \& Sociedade n. 50, São Paulo, p. 87-132, 1996.

RAICHELIS, Raquel. Serviço Social: trabalho e profissão na trama do capitalismo contemporâneo. In: RAICHELIS, Raquel; VICENTE, Damares; ALBUQUERQUE, Valéria (Orgs.). A nova morfologia do trabalho no Serviço Social. São Paulo: Cortez, 2018. 
YAZBEK, Maria Carmelita. Direitos Sociais, Políticas Sociais e Novos Desafios para o Serviço Social. In: RONDON, Elizabeth; ARAÚJO, Sandra Simone de; ROCHA, Sheila (Orgs.). Serviço Social, velhas e novas fronteiras. Rio de Janeiro: Autografia, 2017.

\section{Sobre as autoras}

Maria Carmelita YazbeK - Assistente social. Doutora em Serviço Social. Professora e pesquisadora do Programa de Estudos Pós-Graduados em Serviço Social da PUC-SP.

E-mail:mcyaz@uol.com.br

MARIA InÊs BRAVo - Assistente Social. Doutora e Pós-doutora em Serviço Social. Professora aposentada da Universidade Federal do Rio de Janeiro (UFRJ).

E-mail:mibravo@uol.com.br

Raquel Raichelis Degenszajn - Assistente social. Doutora em Serviço Social. Professora do Programa de Estudos Pós-Graduados em Serviço Social da PUC-SP. E-mail: raichelis@uol.com.br 
